\title{
Extraction Identification Characterization of Saponins from the Myrica Salicifolia Hochst Plant. ex. A. Rich (Myricaceae) and Molluscicidal Activity Test in Vitro
}

\author{
Faustin Safari Habari ${ }^{1}{ }^{\text {* }}$, Charles Muhigirwa Balagizi ${ }^{1}$, Bahati Rusimbuka Marcel ${ }^{1}$, \\ Jean Jacques Bagalwa Mashimago ${ }^{2}$ \\ ${ }^{1}$ Geochemistry and Environment Department, Goma Volcano Observatory, Goma, Democratic Republic of Congo \\ ${ }^{2}$ Malacology Laboratory, Biology Department, Natural Sciences Research Center, Lwiro, Bukavu, Democratic Republic of Congo
}

Email address:

sfaustin53@yahoo.com (F. S. Habari)

*Corresponding author

To cite this article:

Faustin Safari Habari, Charles Muhigirwa Balagizi, Bahati Rusimbuka Marcel, Jean Jacques Bagalwa Mashimago. Extraction Identification Characterization of Saponins from the Myrica Salicifolia Hochst Plant. ex. A. Rich (Myricaceae) and Molluscicidal Activity Test in Vitro. International Journal of Pharmacy and Chemistry. Vol. 6, No. 3, 2020, pp. 26-30. doi: 10.11648/j.ijpc.20200603.11

Received: May 21, 2020; Accepted: June 15, 2020; Published: July 17, 2020

\begin{abstract}
Our study focused on "Extraction identification and characterization of saponins from the plant Myrica salicifolia Hochst. ex. A. Rich and molluscicidal activity test in vitro". The objective of this study is to extract the natural substances present in the different parts (leaves, bark of the stem and roots); isolate the saponins, characterize them by chromatography and determine the lethal dose of the saponins isolated against aquatic molluscs. After the analyzes, the Malacology laboratory of the LWIRO Natural Sciences Research Center (CRSN / LWIRO) took place in the Democratic Republic of Congo in the Kabare Territory. Phytochemical screening has enabled us to observe that saponins, quinones, phenols, lipoids, glycosides, terpenoids, tannoids, flavonoids, and alkaloids are in high concentration while steroids are moderately concentrated in the different parts of the plant. The thin layer chromatography of the saponins shows that the plant contains steroidal and triterpene saponins. The Myrica salicifolia Hochst plant. ex. A. Rich has molluscicidal activity, it can be used in the fight against molluscs Biomphalaria pfeifferi and Lymnaea natalensis intermediate hosts of bilharziasis and fascioliosis. The lethal doses $\left(\mathrm{LD}_{50}\right)$ of the saponin extracts from the bark of the roots and stems were 0.016 and $0.018 \mathrm{mg} / \mathrm{mL}$ respectively for Biomphalaria pfeifferi and 0.022 and $0.021 \mathrm{mg} / \mathrm{mL}$ for Lymnaea natalensis.
\end{abstract}

Keywords: Extraction, Identification, Characterization, Molluscicide Activity Test

\section{Introduction}

In Africa, the therapeutic power of plants was known by our ancestors and our parents empirically [1]. Thus, the chemical composition of the drugs used by many populations for health care was unknown. To achieve an improvement in this African medicine, several phytochemical investigations were made, in order to provide scientific justification for the traditional use of Guédé-Guina plants cited by Zirihi [2].

Plants represent a source of inexhaustible and renewable active ingredients, the traditional and medical use of which has been known for a long time. There is therefore a need to produce isolated, concentrated and purified bioactive substances, for use in a wide field of application (pharmaceutical and nutritional) [3].

Chemically and biologically, several substances of various origins have been isolated and characterized from plants. Some have served to elucidate biological phenomena and to understand certain metabolic pathways have molluscicidal or therapeutic interests.

Schistosomiasis is a parasitic waterborne disease that is prevalent in more than 74 countries and currently affects tropical and subtropical regions around the world [4].

Among the methods of combating this parasitosis, molluscicides are ranked first. It is unfortunately curious to note that certain molluscicides are toxic to the environment and their application requires qualified personnel to use them according to the standards intentionally recognized by the 
World Health Organization. Finally, using molluscicide plant studies to find a simple molluscicide that is less toxic to the environment and easy to apply is a priority for research in the WHO program [4]. Studies have been carried out in R. D. Congo in the Malacology laboratory on the plant Solanum syzymbrilifolium where the presence of solamargine, a molluscicide product, has been detected [5]. The other plants analyzed in this laboratory as molluscicides are Bligha welwitchi, Maesa lanceolata [6], the Myrica salicifolia Hochst plant. e.x. A. Rich is used in fishing for fish by the people of South Kivu and more specifically the people of Idjwi and Bushi.

Many works have been published recently on the species Myrica salicifolia Hochst. e.g. A. Rich, but none of them have addressed the study of molluscicidal saponins, no chemical study has been done to determine the active ingredients that would be found in this plant. It is in this context that this study addresses the study entitled "extraction, identification and characterization of saponins from Myrica salicifolia Hochst. e.x. A. Rich (Myricaceae) to test its molluscicidal activity in vitro".

The Myrica salicifolia Hochst plant. ex. A. Rich is used as a traditional medicine in black Africa, stimulating and as an alternative source of HIV / AIDS. In Uganda the Myrica salicifolia Hochst plant. ex. A. Rich stimulates appetite, increases immunity and treats meningitis, ethnobotanical study $[7,8]$.

In Tanzania Myrica salicifolia Hochst. ex. A. Rich treats diarrhea, herpes simplex and tuberculosis [7].

The Hochst Myrica salicifolia. ex. A. Rich treated malaria in Meru and Kilifi in Kenya. Indeed, methanolic extracts from the roots of Myrica salicifolia Hochst. ex. A. Rich showed in vitro antiplasmodial activity (IC $(50)<100$ microg $/ \mathrm{ml}$ ). This plant was also tested against the salt water shrimp and the test showed that the methanolic extracts were toxic to the salt water shrimp (LD (50) $<100 \mathrm{microg} / \mathrm{ml}$ ), [8]. The Myrica salicifolia plant has several pharmacological effects including: antibiotic, antiviral, antimalaria, analgesic, anticoagulant, anti hypertensive. The extracts of the roots of Myrica salicifolia have an analgesic effect in mice and they show an antipyretic effect in rats but no anti activity inflammatory [9], the Myrica salicifolia Hochst plant, ex. A. Rich, has traditional uses in some areas (South Africa, Ethiopia and Saudi Arabia).

Indeed, the infusion of the roots is used to treat gastrointestinal disorder, while the roots have been used in the treatment of headaches, inflammation and respiratory diseases [10]. The aim of this work is to contribute to the phytochemical study of the Myrica salicifolia Hochst plant

These are especially:

extract the natural substances present in the different parts (leaves, stem bark and root bark) and isolate the saponins, characterize the saponins by thin layer and column chromatography in order to determine their lethal dose to aquatic molluscs, determine the lethal dose against aquatic molluscs.

\section{Materials and Working Methods}

Collecting samples and preparing the powder

The samples of Myrica salicifolia Hochst were harvested in Kahuzi Biega National Park. After collecting the specimens, the bark was dried and then made into a fine powder in a mortar using a pestle. They were sieved through a sieve at the Malacology laboratory of the Center for Research in Natural Sciences (CRSN) in Lwiro. These samples were kept in hermetically sealed plastic bags before laboratory analyzes

Preparation of aqueous extracts

To obtain the aqueous extracts, we took $30 \mathrm{~g}$ of powder from the leaves, $30 \mathrm{~g}$ of bark from the stems and $30 \mathrm{~g}$ of the roots were dissolved in $200 \mathrm{ml}$ of distilled water then we stirred, then we rested the mixture for 24 hours. After a 24 hour maceration, the mixture was filtered. The filtrate was stored in three labeled cylinders.

Preparation of organic extracts

The organic extracts were obtained by dissolving $20 \mathrm{~g}$ of powder from the leaves, $20 \mathrm{~g}$ from the bark of the stems and $20 \mathrm{~g}$ from the roots of the plant in $150 \mathrm{ml}$ of $70 \%$ ethanol. After 24 hours of maceration, the mixture was filtered. The plant extract filtrate was kept in three labeled cylinders.

Saponin extraction

The residues obtained after evaporation of the aqueous extract was reduced in a methanol-water mixture in the proportions (2: 1). The saponins contained in this solution were precipitated by diethyl ether. After evaporation of the solvent, a brown-black residue is obtained. Add a mixture of methanol-diethyl ether $(2: 1)$ to the residue, shake well and leave to stand for 6 hours. The mixtures obtained were poured into the cup tube and subjected to centrifugation for five minutes at the rate of 300 revolutions per second to locate and recover the pellet of the saponins. We moved on to Chromatographic Analysis

Characterization of saponins

To characterize the saponins, we used column chromatography.

Saponin column chromatography

Principle

In liquid or gas chromatography, a fluid called "mobile phase" flows through a tube called "column". In fact, the column is a tube constructed from material that is as inert as possible to chemicals, often stainless steel or glass. Its section is constant, with a diameter between 4 and $20 \mathrm{~mm}$ for lengths generally from 15 to $30 \mathrm{~cm}$. This column can contain porous granules (filled column) or be covered inside with a thin film (capillary column). In both cases, the column is called "stationary phase". At the initial instant, the mixture to be separated is injected at the entry of the column [11].

Separation of saponins

The use of this technique allowed us in our work to fractionate the saponins. The fractions obtained were further subjected to thin layer chromatography. We group together the fractions with the same spots [12].

Preparation of diluted solutions 
The different dilutions of the extracts used in the test were carried out as follows:

The dry residues containing the total active ingredients after weighing them on a precision balance were dissolved in $3 \mathrm{ml}$ of distilled water, the solutions prepared constitute the mother solutions, that is to say highly concentrated;

From the first mother solution, take $1 \mathrm{ml}$ which is diluted to the tenth, that is to say $1 \mathrm{ml}$ of the mother solution plus $9 \mathrm{ml}$ of distilled water, the solution is obtained (2).

From the solution (2), take $1 \mathrm{ml}$ which is diluted in $9 \mathrm{ml}$ of distilled water, we obtain the solution (3).

Molluscicide test

The purpose of this test is to determine whether the saponins extracted from the Myrica salicifolia plant have molluscicidal activity on Biomphalaria pfefferi and Lymnae natalensis in vitro. Molluscicide harvest.

The molluscs that we used in our activity tests are: Biomphalaria pfefferi and Lymnae natalensis. These molluses were collected from the marshes surrounding the Lwiro Natural Sciences Research Center. They were collected using a haze net and transported to the laboratory in vials.

Six living individuals of Biomphalaria pfefferi and six of Lymnae natalensis were introduced into each cylinder containing the active ingredient of the plant, 24 hours after the molluscs were washed with tap water. The counting was carried out and we counted all the dead and alive molluscs, a negative control was made up containing the molluscs in distilled water.

\section{Results and Discussions}

Phytochemical screening

The following natural substances have been detected in the plant Myrica salicifolia Hochst. e.g. A. Rich (Myricaceae) thanks to phytochemical screening.

Table 1. Results of phytochemical screening of plants according to the different parts.

\begin{tabular}{llll}
\hline Natural substances & Leaves & Stems & Roots \\
\hline Alkaloids & ++ & +++ & +++ \\
Flavonoids & ++ & +++ & +++ \\
Tannoids & ++ & +++ & +++ \\
Terpenoids & +++ & +++ & +++ \\
Steroids & + & ++ & ++ \\
Glycosides & ++ & +++ & +++ \\
Lipoids & +++ & +++ & +++ \\
Phenols & +++ & +++ & +++ \\
Quinones & +++ & +++ & +++ \\
Saponins & +++ & +++ & +++ \\
\hline Caption: & & & \\
$+:$ Low concentration. & & & \\
$++:$ Medium concentration. & & & \\
$+++:$ High concentration. & &
\end{tabular}

It appears from Table 1 of the phytochemical screening of Myrica salicifolia Hochst, that high concentrations of Saponins, quinones, phenols, lipoids, glycosides, terpenoids, Tannoids, Flavonoids, Alkaloids are observed more in the roots than in the leaves and moderately in the stems. On the other hand, steroids have a low concentration on average throughout the plant. These natural substances detected in the Myrica salicifolia Hochst plant, are responsible for the therapeutic effects found in the plant [7-9].

Thinlayer chromotography

The results of the thin layer chromatography of total saponins from different parts of the plant Myrica salicifolia Hochst.

Legend: R1 and R2=Root extracts; $\mathrm{T} 1$ and $\mathrm{T} 2=\mathrm{Rod}$ extracts; F1 and F2=Leaf extracts; $\mathrm{D}=$ Digitonin.

After the analyzes by thin layer chromatography, it appears that there is the presence of saponins which have migrated to the following retention factors (Rf): $0.142 ; 0.428$; and 0.714 . One of saponin or the structure of digitonin is similar in that they have the same retention factors (Rf). This has also been observed in the Solanum synzybrilifolium plant by other researchers [5].

chromatography

The mixtures of the extracts (R1-R2), (T1-T2) and (F1-F2) were respectively subjected to separation by column chromatography. 18 (6x3) different tubes were collected and analyzed separately by thin layer chromatography.

Separation of saponins by thin layer chromatography after column chromatography of three parts of the plant Myrica salicifolia Hochst.

From this plaque it appears that there is presence in Myrica salicifolia Hochst saponins of two categories, namely: steroidal saponins which occupy the lower part of the plate (polar) and terpene saponins which occupy the upper part of the plate (less polar). The different retention factors (Rf) are respectively: $0.166,0.500$, and 0.833 . From the above, we observe that these different saponins are concentrated only in the roots and in the stems.

Saponin activity test

The results of the molluscicidal activity test on the biomphalaria pfeifferi and lymneae natalensis molluscs of saponins isolated by column chromatography are presented in Tables 2 and 3.

Table 2. Activity of the saponins isolated on Biomphalaria pfeifferi.

\begin{tabular}{lllll}
\hline $\begin{array}{l}\text { Concentration } \\
(\mathbf{m g} / \mathbf{m L} \mathbf{)}\end{array}$ & Roots & Stems & Leaves & $\begin{array}{l}\text { Negative } \\
\text { control }\end{array}$ \\
\hline 0,33 & 100 & 100 & 0 & 0 \\
0,033 & 100 & 100 & 0 & 0 \\
0,0033 & 17 & 0 & 0 & 0 \\
0,00033 & 0 & 0 & 0 & 0 \\
\hline
\end{tabular}

It appears from table 2 that at the concentrations of 0.33 $\mathrm{mg} / \mathrm{ml}$ and $0.033 \mathrm{mg} / \mathrm{ml}$ all the individuals of Biomphalaria pfeifferi are killed; at the concentration 0.0033 $\mathrm{mg} / \mathrm{ml} 17 \%$ of Biomphalaria pfeifferi die for the extracts of the roots and all individuals have resisted for the extracts of the stems; at a concentration of $0,00033 \mathrm{mg} / \mathrm{mL}$ all Biomphalaria pfeifferi species resisted extracts from the bark of the roots as well as from the stems. For the leaves, all individuals withstood even high concentrations.

Previous studies show that the aqueous extract of the cassia didymobotrya plant, at a concentration of $0.020 \mathrm{~g} / \mathrm{mL}$, 
kills $40 \%$ of Biomphalaria pfeifferi. At the concentration of $0.1 \mathrm{~g} / \mathrm{mL}$ all individuals are killed and at the concentration $0.0001 \mathrm{~g} / \mathrm{mL}$ all individuals resisted for the plant extracts Turracantus africanus.

Table 3. Activity of saponins isolated on Lymnaea natalensis.

\begin{tabular}{lllll}
\hline $\begin{array}{l}\text { Concentration } \\
(\mathbf{m g} / \mathbf{m L})\end{array}$ & Roots & Stems & Leaves & $\begin{array}{l}\text { Negative } \\
\text { control }\end{array}$ \\
\hline 0,33 & 100 & 100 & 0 & 0 \\
0,033 & 100 & 80 & 0 & 0 \\
0,0033 & 60 & 0 & 0 & 0 \\
0,00033 & 0 & 0 & 0 & 0 \\
\hline
\end{tabular}

From this table, it appears that at concentrations $0.33 \mathrm{mg} /$ $\mathrm{ml}$ and $0.033 \mathrm{mg} / \mathrm{ml}$ all the individuals of Lymnaea natalensis are killed; at the concentration $0.033 \mathrm{mg} / \mathrm{ml} 100 \%$ of Lymnaea natalensis die for the extracts of the roots, for the extracts of the stems $80 \%$; at the concentration $0.0033 \mathrm{mg} /$ $\mathrm{ml}, 60 \%$ die for the extracts of the roots and for the stems all individuals have resisted; and at the concentration $0.00033 \mathrm{mg} / \mathrm{mL}$, all the individuals of Lymnaea natalensis resisted.

Some researchers have shown that the Myrica salicifolia plant is used as an alternative source of HIV / AIDS, treats meningitis, anti-inflammatory, treats diarrhea, treats tuberculosis [7, 8], unlike us, we have found that this Myrica salicifolia plant can be used to control Lymnaea natalensis molluscs.

Determination of lethal doses $\mathrm{LD}_{50}$

The lethal doses of the saponins from the roots and stems of the Myrica salicifolia plant were calculated and the results are presented in Table 4 below.

Table 4. Lethal doses $L D_{50}$ of the different extracts of saponins.

\begin{tabular}{lllll}
\hline & \multicolumn{2}{l}{ Biomphalaria pfeifferi } & \multicolumn{2}{c}{ Lymnaea } \\
\cline { 2 - 5 } & Roots & Stems & Roots & Stems \\
\hline $\mathrm{DL}_{50}(\mathrm{mg} / \mathrm{mL})$ & 0,016 & 0,018 & 0,022 & 0,021 \\
\hline
\end{tabular}

The $\mathrm{LD}_{50}(\mathrm{mg} / \mathrm{mL})$ are respectively: $0.016 \mathrm{mg} / \mathrm{mL}$ and $0.018 \mathrm{mg} / \mathrm{mL}$ for the extracts of myrica salicifolia tested against Biomphalaria pfeifferi, a concentration of $0.0044 \mathrm{gmL}$ for the ethanolic extract and $0.0022 \mathrm{~g} / \mathrm{mL}$ for the aqueous extract of the plant Turracantus africanus against Biomphalaria pfeifferi. Some authors [8], have also shown that the methanolic extracts of the roots of myrica salicifolia have an antiplasmodial activity in vitro $\left(\mathrm{IC}_{50}<100\right.$ micro $/ \mathrm{mL}$ ) and these extracts have also been tested against shrimp of 1 salt water $\left(\mathrm{LD}_{50}<100 \mathrm{micro} / \mathrm{mL}\right)$. Unlike us, we found that at concentrations $0.016 \mathrm{mg} / \mathrm{mL}\left(\mathrm{LD}_{50}\right)$ and $0.018 \mathrm{mg} / \mathrm{mL}$ $\left(\mathrm{LD}_{50}\right)$ extracts of myrica salicifolia are used against Biomphalaria pfeifferi and at concentrations $0.022 \mathrm{mg} / \mathrm{mL}$ $\left(\mathrm{LD}_{50}\right)$ and $0.021 \mathrm{mg} / \mathrm{mL}\left(\mathrm{LD}_{50}\right)$ against Lymnaea natalensis.

\section{Conclusion}

Our work entitled "Extraction, identification and characterization of saponins from the plant Myrica salicifolia Hochst ex. A. Rich (Myricaceae) and test molluscicidal activity in vitro" mainly aimed at extracting the natural substances present in the different parts ( leaves, stem bark and root bark) of the Myrica salicifolia plant, isolate the saponins found in the plant, characterize the saponins by thin layer and column chromatography, and determine the lethal dose against some aquatic molluscs (Biomphalaria pfeifferi and Lymnae natalensis).

We have carried out phytochemical screening of the plant Myrica salicifolia to ensure the presence of saponins recognized as molluscicides against molluscs intermediate hosts of bilharziasis and fascioliasis.

Following our investigations, the following results were obtained:

Phytochemical screening has shown that the Myrica salicifolia plant contains the following natural substances: saponins, quinones, phenols, lipoids, glycosides, terpenoids, tannoids, flavonoids, alkaloids in high concentration while steroids are in medium or low concentration. The bark of roots and stems has high concentrations compared to leaves which contain only low concentrations. The thin layer chromatography of the saponins gave different spots in the extracts of the roots, stems but no spots were observed for the extracts of the leaves. The Myrica salicifolia plant contains steroid and terpene saponins. The molluscicidal activity of these saponins shows an $\mathrm{LD}_{50}$ of $0.016(\mathrm{mg} / \mathrm{mL})$ for the extracts of the roots and $0.018(\mathrm{mg} / \mathrm{mL})$ for the extracts of the stems with respect to Biomphalaria pfeifferi, and $\mathrm{LD}_{50}$ of $0.022(\mathrm{mg} / \mathrm{mL})$ and $0.021(\mathrm{mg} / \mathrm{mL})$ for lymneae natalensi respectively for the bark of the roots and stems.

\section{References}

[1] NyakabwaM., 1990. Medicinal plants used in the banyamulenge of Fizi in South Kivu (Zaire), Faculty of Science, University of Kisangani, $14 \mathrm{p}$.

[2] Zirihi G. N., 2006. Botanical, pharmacological and phytochemical studies of some anti-malarial and / or immunogenic medicinal plants used in the Bété of the Department of Issia, in the west of Coted'Ivoire. State Doctorate Thesis, University of Cocody-Abidjan, UFR Biosciences, 126p.

[3] P. enchew, 2010. Study of the extraction and purification processes of bioactive products from plants by coupling separation techniques at low and high pressures. Doctoral thesis, Institut National Polytechnique de Toulouse Discipline or specialty: Process and Environmental Engineering, 239p.

[4] Kloos et MCullough F. S., 1981. Plant molluscicid: A review, Geneva, document no WHO/VBC/813.834-WHO/SCH/81.59, $33 \mathrm{p}$.

[5] Bagalwa M., Voutquenne-Nazabadioko L., Sayagh C., Bashwira S., 2010. Evaluation of the biological activity of the molluscicidal fraction of Solanum sisymbriifolium against non target organisms, Fitoterapia, 81, 767-771.

[6] Bagalwa M., Chifundera K., 2007. Environnemental impact evaluation of the Stem barks extract of Maesa lanceolata used in Democratic Republic of Congo. Journal of Ehno pharmacology, 114, 281-284. 
[7] Maroyi A., 2014. Alternative Medicines for HIV/AIDS: Insight from Traditional Medicines Use in Sub-Saharan Africa Tropical Journal of Pharmaceutical Research, ISSN: 15965996, 9p.

[8] Kirira P. G, Rukunga G. M,, Wanyonyi A. W., Muregi F. M, Gathirwa J. W, Muthaura C. N,, Omar S. A, Tolo F,, Mungai G. M, Ndiege O., 2011. Anti-plasmodial activity and toxicity of extracts of plants used in traditional malaria therapy in Meru and Kilifi Districts of Kenya.

[9] KNjung'e, Gichuru M., Josphat M. i, Kuria K., 2002. Analgesic and effets antipyrétic of Myrica salicifolia.
[10] Silva B. J. C., Ana M. L., 2015. Recent Breakthroughs in the Antioxidant and Anti-Inflammatory Effects of Morella and Myrica Species, International Journal of Molecular Sciences, ISSN 1422-0067, 20p.

[11] Jhoo J-W., Sang S., He K., Cheng X., Zhu N., Stark RE., Zheng Q. Y., Rosen RT,; Ho CT., 2001. Characterization of the triterpene saponins of the roots and rhizomes of bluecohosh (caulophyllum thalictroides). J. Agric. Food. Chem. 49p.

[12] Vauquenne L., Kokougan C., Pouny I., Litoudon M., 2002. Triterpenoid saponines and acyclated, prosapogenins from Harpullia austro-coledsnica. Phytochemistry, 59p. 